\title{
Reflecting on Reflection: Scale Extension and a Comparison of Undergraduate Business Students in the United States and the United Kingdom
}

\author{
James W. Peltier \\ Professor of Marketing \\ University of Wisconsin-Whitewater \\ College of Business \& Economics \\ Whitewater, WI 53190 \\ Voice: 262-472-5474 \\ Fax: 262-472-4863 \\ peltierj@uww.edu \\ Amanda Hay \\ Nottingham-Trent University \\ Nottingham Business School \\ Nottingham NG1 4BU \\ Voice: $0115-848-4364$ \\ Fax: $+44(0)-115-948-6512$ \\ amanda.hay@ntu.ac.uk \\ William Drago \\ University of Wisconsin-Whitewater \\ College of Business \& Economics \\ Whitewater, WI 53190 \\ Voice: 262-472-3994 \\ Fax: 262-472-4863 \\ dragow@uww.edu
}




\section{Reflecting on Reflection: Scale Extension and a Comparison of Undergraduate Business Students in the United States and the United Kingdom}

In the Peltier, Hay, and Drago (2005) article entitled "The Reflective Learning

Continuum: Reflecting on Reflection," a reflective learning continuum was conceptualized and tested. This is a follow-up article based on three extensions: (1) determine whether the continuum could be expanded, (2) further validating the continuum using additional schools, and (3) determining whether the continuum could also be applied to undergraduate business education. The findings from a study of U.S. and UK students show that the revised scale is valid and reliable and that U.S. students in the sample universities rated their educational experience higher and were more likely to use reflective thinking practices. 


\section{INTRODUCTION}

The previous article in this issue of the Journal of Marketing Education (Peltier, Hay, and Drago, 2005) entitled "The Reflective Learning Continuum: Reflecting on Reflection," reviewed the reflective learning literature, conceptualized a reflective learning continuum, utilized an instrument to measure student learning along this continuum, and presented findings from an empirical study showing the validity and reliability of measures of reflective learning (and non-reflective learning) across the proposed continuum. Based on that research, the manuscript reviewers and JME editor recommended three extensions to consider: determining whether the continuum could be expanded to include additional dimensions, (2) further validating the continuum using additional schools, and (3) determining whether the continuum could also be applied to undergraduate business education.

This follow-up study is designed to further develop, test, and implement the reflective learning continuum on a global scale. Consistent with the recommended extensions, the article has three objectives. First, as with any continuum, some overlap exists at the intersection of various dimensions along that continuum. With this in mind, we expand the number of items in our reflection questionnaire for the purpose of better delineating dimensions along the reflective learning continuum. Second, partially in response to the business community and AACSB concerns for developing decision making skills in graduate students, our first manuscript validated the reflective learning instrument using a sample of recent alumni from an MBA program. Here, we take our revised continuum and examine whether reflective thinking is an important component of undergraduate business education. Because graduate and undergraduate students often exhibit disparate patterns of behaviours and learning approaches (Clarke and Flaherty, 2002), cross-validation across these two student populations is important. Third, 
concerns surfaced regarding whether the validity of our reflective learning continuum was in any way compromised given that our initial study utilized students from a single U.S. university. To address this concern we validate our revised reflective learning continuum using undergraduate students in the U.S. and the United Kingdom. This approach has two benefits. First, we are able to show the validity of our revised reflective continuum across different universities and on a more global scale. Second, we generate a better understanding of how U.S. and U.K. business programs utilize reflective learning in their curricula. Given the increased internationalization of business education, and the paucity of literature examining educational needs across cultures and nationalities, research aimed at understanding global learning styles is warranted (Clarke and Flaherty, 2003; Duff, 2001; Jones, 2003; Ledith and Seymour, 2001; Marriott, 2001; Mellahi, 2000), especially as they relate to reflective learning practices (Catterall et al., 2002).

Given that our previous paper presented a detailed review of the reflective learning literature, we will focus on a more limited set of studies, particularly those that relate to our proposed extensions. To generate a clearer picture of U.K. and U.S. business programs, we then provide background information on the two schools investigated in our study, paying particular attention to comparing and contrasting the two programs. As with the previous study, we then present the findings in terms of identified dimensions along the reflective learning continuum, paying specific attention to those that impact perceptions of perceived program quality. From there we analyze and compare the findings for each dimension across the two global business programs. We conclude with a discussion on important implications and directions for future research. 


\section{REFLECTIVE LEARNING CONTINUUM}

\section{Stages in the Reflective Learning Continuum}

Based on the past literature reviewed in Peltier, Hay and Drago (2005), we define the reflective learning continuum as "a series of increasingly deep learning stages that may be utilized by individuals to integrate new information, contemplate its meaning and relevance in terms of past knowledge, and culminating in the decision of whether to modify existing beliefs and assumptions, future learning styles and/or behaviors based on what was learned." These stages include habitual action, understanding, reflection, and intensive reflection. Brief summaries and our definition of each of these stages are presented below.

Habitual Action/Learning occupies the least thoughtful and motivated end-point on the reflective learning continuum. This type of learning minimizes the need for active engagement (Leung and Kember, 2003), and as a result, reflective thinking is replaced by routinized actions (Cope, 2003; Meizirow, 1991). We define habitual action/learning as a non-reflective learning process that takes place without thought or reflection, often through memorization.

Understanding relates to comprehension without the need to actively relate what is learned to past learning situations or experiences (Kember et al., 2000). Understanding has two levels, learning concepts and application of those concepts (Leung and Kember, 2003). Although understanding requires more active engagement than habitual action, it is still characterized as non-reflective thinking in that what is learned is not personally assimilated or evaluated in terms of one's past experiences (Mezirow, 1991). We define understanding as a thoughtful though nonreflective learning process in which the learner comprehends but does so within pre-existing perspectives. 
Reflection is the first of two higher-order processing components on the reflective learning continuum. In addition to understanding course content, reflective thinking involves critiquing firmly held assumptions about what is learned (Kember et al., 2000). A key component of reflective learning is the questioning of one's experiences in light of what is being learned, which in turn encourages the thoughtful consideration of a wider range of alternative courses of actions (Atkins and Murphy, 1993; Pee et al., 2000). We thus define reflection as a move beyond comprehension of learning material to a more active engagement in learning which evokes previous knowledge and experience, involves a questioning of what is learnt and may include a search for alternative explanations. Ultimately, the goal is to develop in students the ability to appraise their experiences, identify new solutions to problems, improve on past actions, and think about the wider implications of their experiences.

Critical/Intensive Reflection is the deepest and most thoughtful element of the reflective learning continuum. Intensive reflection represents a deeper form of reflection and moves from questioning assumptions and viewpoints to changing conceptual meanings, altering internal perspectives, and modifying future behaviours (Boyd and Fales, 1983; Kember, et al. 2000). Creating "perspective transformation" is the highest of all learning goals and helps prepare students for life-long learning (Peltier, Hay, and Drago, 2005). Based on this review, we define intensive reflection as a deeper degree of reflection whereby the individual's learning experience stimulates changes in firmly held beliefs and assumptions, and ultimately, future behavior.

\section{Conditions for Reflection}

Student-to-Student and Instructor-to-Student Interactions are two key conditions for reflection. Combined, interactions by members of the learning community are key to the ultimate success of the educational process (Peltier, Drago, Schibrowsky, 2003). In many ways, 
higher-order reflection will only occur when all individuals in the learning community are motivated by and feel comfortable with their instructor and fellow students, and are thus able to express doubt, to explore uncertainties, and to become aware of internal and external contradictions (Boud et al., 1985).

\section{Summary of Findings and Proposed Extensions}

In the 2005 Peltier, Hay and Drago study, all four of the preceding elements of the reflective learning continuum and the two conditions for reflection were found to have a significant impact on the perceived quality of the learning experience. Moreover, as expected, learning situations motivating habitual action and mere understanding of materials negatively impacted perceived quality of the educational experience. In contrast, learning environments that required reflection and intensive reflection were associated with higher quality learning experiences. Also as predicted, intensive reflection had the greatest impact on quality perceptions, followed by reflection, understanding, and habitual action, substantiating the hierarchical nature of the continuum.

Although the original reflective learning questionnaire proved to be both valid and reliable, it was constructed and tested through responses from alumni from a single MBA program located in the U.S. We were particularly interested in determining whether the reflective learning continuum and the conditions for reflection could be cross-validated using undergraduate students in the U.S. and the UK. Moreover, as previously noted there was some overlap or grey areas on the habitual action and understanding dimensions of the continuum. As a consequence, additional questions were added in an attempt to tap surface and deep approaches to learning (Biggs et al 2001) and which have been hypothesized to impact reflection (Leung and Kember, 2003). In addition, given that our previous study suggested understanding was 
negatively correlated to program outcomes, it was further suggested that understanding may take various forms: Basic and Deep Understanding.

Basic and Deep Understanding: We expect to further develop the understanding dimension from Peltier, Hay and Drago, (2005) by distinguishing a basic or superficial understanding (Basic Understanding) from a more strategic or applied understanding (Deep Understanding).

Deep Processing: As suggested by Biggs (1987), deep learning is seen to involve an active search for understanding where the learner shows interest and enjoyment in the learning process as opposed to a surface learner who tries to minimize study time. As stated above, deep processing may be seen as a prerequisite for reflection and intensive reflection. Our revised model and expected relationships are presented in Figure 1.

\section{HIGHER EDUCATION IN THE UNITED KINGDOM}

Although the reflective learning construct is receiving increased empirical investigation in a number of host countries and cultures, including the U.S. (Peltier, Hay, and Drago 2005, Hay, Peltier, and Drago, 2004), Hong Kong (c.f., Kember, Biggs, and Leung, 2004; Kember and Leung, 2005; Leung and Kember, 2003), Canada (Loo, 2002), the United Kingdom (Harrison, et al., 2003; Mcalellan, 2004), the Netherlands (van Woerkom 2004; van Woerkom et al., 2002), and Finland (Liimatained et al., 2001), virtually no studies exist that compare U.S. and global business programs on elements of the reflective learning continuum and conditions for reflection. In this section we provide some background on higher education and business education in the U.K., along with some comparisons to the U.S..

\section{UK Higher Education}

Within recent decades, higher education in the UK has witnessed extensive change in terms of student numbers, funding and program structures. The government is requiring 
universities to accept increased student numbers, heralding a move from an elite system to a mass system of higher education (Eriksen, 1995). This encompasses the government's 'widening participation' agenda which aims to encourage applications from those whose participation in higher education is low, such as the working class and ethnic minorities. By 2010, the government aims for $50 \%$ of 18 to 30 year olds to experience higher education a lofty goal but still far short of the number of North Americans who participate in some form of higher education (Government White Paper, 2003). Changes in the funding of higher education have also been evident with the abolition of student maintenance grants and an increasing onus on the student to obtain financial support for their education in the form of loans which are repaid upon completion and an increasing reliance on part time work. In 2006, 'top up fees' will be introduced, allowing the individual university some discretion in charges for individual programs which might be seen to mimic new right inspired market approaches along capitalist lines as seen in the U.S. (Slaughter and Leslie, 1997).

Along with this more open education system there have also been attempts to increase the flexibility of program delivery in the UK, with moves towards modularisation, accreditation of prior learning and credit accumulation transfer (Mullins and Roberts, 1996). This has meant a rejection of traditional delivery systems passed down from Oxbridge where students were assessed exclusively at the end of their programs in a set of 'final' examinations. U.K. students now typically receive a form of ongoing assessment at the end of each course (yearly or half yearly) which may take the form of an examination and or coursework, accumulating 'credits' which can be transferred between programs and even institutions.

Students typically enter Higher Education at the age of 18, with entry being dependent upon performance in A-level examinations. Most undergraduate programs are three years full 
time with some programs, notably those in business, offering a placement or sandwich year in industry, taken at the end of year two. In terms of program content, in higher education there have been recent moves to implement skill based curricula which address calls for increased attention to graduate employability following the Dearing Report (1997). Teaching in undergraduate programs is fundamentally structured around a lecture and tutorial program, with an expectation of student directed learning between sessions.

\section{Comparisons to U.S. Programs}

Literature which compares U.S. and U.K. business programs is scant. Traditionally, U.K. programs have relied heavily on final examinations as opposed to the U.S. which utilize not only more diverse forms of assessment but also more regular assessment throughout the program. However, as stated above there have been significant changes in U.K. Higher Education particularly in respect to program structures which are becoming increasingly similar to the US. The literature does suggest that although U.K. programs have increasingly utilized more diverse assessment techniques, the use of examinations relative to the U.S. is high, which could compromise the opportunity for critical learning (Clarke and Flaherty, 2002).

In partial support of this view, Clarke and Flaherty (2002) conducted a study comparing U.S., U.K., and Chinese students on perceptions of the value of various educational tools. While the study did not focus explicitly on reflective learning, some meaningful differences were found that are relevant to the current study regarding U.S. and U.K. business programs. As an example, U.K. students placed greater value on academic readings, most notably those associated with exams. In contrast, U.S. students placed greater value on practioner-based business articles, real world business speakers, solving business problems, and strategic computer simulations, all of which may be useful educational tools for motivating reflection and intensive reflection. Also of 
interest, Internet communications between students and instructors were more important for U.S. students. This may be an indication of greater professor/student interaction, which is believed to be an important prerequisite condition needed for reflection. No differences were found for value placed on lectures and lecture outlines, items often associated with the understanding construct (Hay, Peltier, and Drago, 2004). Similarly, no significant differences were found for case studies and marketing plans, educational tools that could be used to generate reflection and intensive reflection. In another study, Billing (2003) asked key higher education stakeholder groups in the U.S. and U.K. to rank the most important skills or attributes required of graduates entering the workforce. The highest ranked skill/attribute set for U.S. graduates was analytical, evaluative, logical and critical skills, conceptual thinking and diagnosis, which was ranked ninth by U.K. respondents. In the U.K. communication skills were ranked first (which ranked second in the U.S.). The next most important skill set in the U.K. was team-work, group skills, and collaborativeness, which was ranked $12^{\text {th }}$ in the U.S. sample. Whether this higher ranking of teamwork in the U.K. leads to an emphasis on group work and thus greater student-to-student interaction in the course room is not known.

\section{THE STUDY}

\section{Background and Sample}

To address the research objectives outlined earlier, a study was conducted using undergraduate students in the U.S. and the U.K. who were enrolled in the capstone business strategy course for each program. The capstone course was used to ensure that respondents were at the end of their business program. In responding to the need to further delineate the reflective learning continuum, particularly with regard to the habitual learning and understanding dimensions, new questions were added to the original list of questions from the Peltier, Hay, and 
Drago (2005) study. As before, the results were factor analyzed, and the final dimensions were made up of those questions that loaded highly on particular dimensions and contributed to the reliability of those learning dimensions.

\section{Comparison of Target Business Programs}

Table 1 summarizes the similarities and differences between the two business programs investigated in this study. As can be seen in Table 1, some similarities can be found in the two programs. Both of the programs are relatively large in size, have considerable overlap in required courses, service a traditional student population, and although credits are counted differently, both programs have an internship/co-op program (though the U.K. school is more formalized and last an entire year), and have a relatively equal number of contact hours needed for graduation over a similar time-frame. In addition, the types of students served and courses offered are relatively consistent across the two business programs. Both universities enjoy high placement rates in industry for their graduates and have strong reputations with numerous award winning programs.

There are some notable differences between the two programs as well. The U.S. program is regionally based and accredited by AACSB International, whereas the U.K. program has a national market and is not accredited. However, the U.K. program was selected as one of the top 15 business programs in the U.K. (Guardian, 2004). The U.S. program is organized around majors and students seem to have greater scheduling flexibility, compared to a more lock-step program in the U.K. The U.S. program generally has smaller class sizes (30-50 students) while the U.K. program utilizes a combination of large (250 student) lectures and smaller (15 student) seminars. Another apparent difference is the greater use of lectures in the U.K. versus a greater emphasis on case analyses through groups or teams in the U.S. program. 


\section{Hypotheses Based on Literature Review and Differences in Learning Environments}

The limited comparative research on reflective learning between the U.S. and U.K. in higher education provides little indication that institutions in one country may exceed those of the other country in terms of performance along the reflection hierarchy. In considering these two specific institutions it is believed that students from the U.S. program may have higher perceptions of professor-to-student and student-to-student interactions due to the overall use of smaller classes and the emphasis on group work and case analyses. This may then lead to higher perceptions of deep processing, deep understanding, reflection and intensive reflection in their business program, and a higher overall perception of program quality. The greater flexibility given students in terms of when to take courses and through selection of their major, what courses they will take, may also lead to higher levels of deep processing. If this is the case then we would in turn expect students in the U.K. program to have perceived higher levels of habitual action and basic understanding.

H1: U.S. students will have higher levels of intensive reflection.

H2: U.S. students will have higher levels reflection.

H3: U.S. students will have higher levels deep understanding.

H4: U.S. students will have higher levels of deep processing.

H5: U.K. students will have higher levels of habitual action.

H6: U.K. students will have higher levels of basic understanding.

H7: U.S. students will rate professor interactions higher.

H8: U.S students will rate student interactions higher.

H9: U.S. students will rate the overall program learning experience higher.

\section{Questionnaire Development and Procedure}

The 56 reflection questions used in Peltier, Hay, and Drago (2005) served as the base questionnaire, to which an additional eight items were added to more deeply elaborate the habitual action and understanding continuum elements. As before, students responded to six global dependent measures regarding the value of their overall learning experience while in the 
program: I learned a lot in the Business Program, I enjoyed the Business Program, I would recommend the Business Program to others, The Business Program has benefited my career, The Business Program has benefited my life generally, and Overall, I am satisfied with the Business Program. These six items were summed together and an average score was calculated for each student. All items were measured via a 5-point Likert type scale that ranged from $1=$ strongly agree to $5=$ strongly disagree. The questionnaires were distributed in multiple sections of what is equivalent to the capstone course in each program. A total of 158 U.S. students and 161 UK students completed the questionnaire, a response rate of approximately $70 \%$.

\section{FINDINGS}

\section{Validating Dimensions of the Reflective Learning Continuum}

One of the objectives of the study was to extend and validate the dimensions of the reflective learning continuum using undergraduate students and a more global student population. Initially, the questionnaire items were factor analyzed using the exact procedure from Peltier, Hay and Drago (2005). The resulting factor analysis findings are presented in Table 2. As expected, six reflective learning dimensions emerged along with the instructor-tostudent and student-to-student interaction dimensions. The coefficient alphas ranged from .55 to .84 , with seven of the eight dimensions exceeding .70, indicating acceptable levels of reliability.

Consistent with Peltier, Hay and Drago (2005), we again ran two regressions to assess the validity of the dimensions on the reflective learning continuum: one with the six reflection dimensions and one that included the conditions for reflection. The dependent variable is the summed six program evaluation measures used In Peltier, Hay and Drago (2005) study discussed above. The findings are shown in Table 3 and Table 4. From Table 3 it is evident that all six of the continuum dimensions had a significant impact on the overall perceptions of the business 
program with intensive reflection again the most important dimension. As shown in Table 4, all six of the reflective learning dimensions and the two conditions for reflection significantly impacted perceptions of program quality, with intensive reflection maintaining its position as the most important learning dimension. Of interest, with the addition of deep understanding and deep processing in the model, arguably two learning criteria sparked by the instructor, instructorto-student interactions was the second most important learning dimension. Importantly, the regression results support the view that our reflective learning instrument was found to be valid for assessing program quality for undergraduate students and for the universities studied in the U.S. and the U.K.

\section{U.S. vs. UK Students and Programs}

Two different data analytic techniques were used to test whether students in the U.S. sample differed from their U.K. counterparts across the reflective learning continuum and conditions for reflection. We first created an average summed score for each dimension. To test the directional hypotheses we then ran one-tailed t-tests to compare U.S. and U.K. students. We then compared U.S. and U.K. students on individual reflection and condition for reflection questions.

\section{Comparison of Summed Dimension Scores}

Table 5 shows the average summed score for each of the six reflective learning dimensions and the two conditions for reflection. Consistent with expectations, U.S. students reported that their business program generated greater reflection $(2.0$ vs. $2.18, \mathrm{p}<.001)$, that they engaged in a higher level of deep processing ( 2.91 vs. $3.05, \mathrm{p}<.05)$, and that instructors were more involved in creating a reflective learning atmosphere in the classroom ( 2.18 vs. 2.48 , 
$\mathrm{p}<.001$ ). In contrast, U.K. students perceived a greater level of basic understanding in their business program $(2.78$ vs. $3.13, \mathrm{p}<.001)$.

The average summed score across the six overall program evaluation statements is also presented in Table 5. From Table 5 it can be seen that U.S. students evaluated their learning experience at a significantly higher level than did U.K. students $(1.93$ vs. $2.30, p<.001)$, supporting H9.

\section{Comparison of Individual Questions by Dimension}

Summed dimensions alone are insufficient for detecting differences between U.S. and U.K. students, particularly if some of the non-significant statements are in opposite directions and thus reduce and/or eliminate a statistical difference in the summed means. Table 6 presents the significant differences for the individual questions for each of the reflective learning dimensions and conditions for reflective learning. The questions are sorted by the mean differences for U.K. and U.S. students. A negative mean difference indicates more agreement by U.S. students. Importantly, the analysis of individual questions revealed some meaningful differences in addition to those found from the summed dimensions.

Intensive Reflection: Although the summed dimensions was not significant, U.S. students were in stronger agreement that 'What I learned changed how I will do things in the future' and 'I learned many new things about myself’. This provides partial support for H1.

Reflection: The three greatest differences were that U.S. students were in much stronger agreement that 'I often tried to think about how I could do things better next time', 'I often reappraised my experiences so that I could learn from them', and 'I tried to think about my strength and weaknesses'. Of interest, U.K. students were more likely to agree that 'I often questioned whether I was doing things right', which post hoc could be a function of less 
interaction with professors. Combined with the summed finding, this provides strong support for H2.

Deep Processing: The three significant differences were that U.S. students were in greater agreement that 'I worked hard at my studies because I found the program interesting', 'I found topics interesting and spent extra time seeking information', and 'I read it even if it wasn't required'. Combined with the summed finding, this provides strong support for H3.

Deep Understanding: The summed dimension was not significant, though U.K. students were in greater agreement that 'many assignment and tests focused on assessing concepts and theories'. Weak support for H4.

Habitual Action: No significant differences were found for H5.

Basic Understanding: U.K. students were in much greater agreement that 'Understanding what was in the assigned text was more important than understanding how it applied to the current business world', 'If it was not going to be evaluated, we should not have had to study it', and 'Content of most courses was interesting but not very relevant to the real world'. Combined with the summed finding, this provides strong support for H6.

Instructor-to-Student Interactions: The four largest differences between U.S. and U.K. students were that U.S. students were in much greater agreement that their instructors 'Valued my opinions', 'Created an atmosphere that allowed me to be open about my views', 'Challenged me to think', and 'Encouraged me to think about the implications of what I learned'. Combined with the summed finding, this provides strong support for $\mathrm{H} 7$.

Student-to-Student Interactions: Although the summed dimension was not significant, U.S. students were in greater agreement that 'I was able to voice my opinion without fear of ridicule by other students' and 'I thought about what other students did and tried to think of better ways', 
two issues that are likely to contribute to reflection and intensive reflection. This provides partial support for $\mathrm{H} 8$.

Summary of Hypotheses: Of the exploratory hypotheses, only habitual action and deep understanding did not receive any support.

\section{DISCUSSION}

In this study we set out to accomplish three objectives: to further clarify and evaluate the reflective learning continuum, to test our reflective learning continuum on a population of undergraduates (as opposed to alumni of an MBA program in the first study) to determine if the same dimensions would be found and also to determine if these dimensions would be important predictors of student satisfaction with the program, and to expand our study beyond one institution to include an additional program from another country in the hopes of creating a more global model and measurement instrument for the reflection hierarchy. Importantly, the latter objective also included a desire to generate an enhanced understanding of international differences in business programs. We feel that progress has been made across all three of our objectives.

\section{Increasing Model Clarity}

Two new factors were uncovered in terms of the reflective learning continuum: namely Deep Understanding and Deep Processing. Deep Understanding may be seen to encompass a fuller understanding which involves a certain level of applied or strategic understanding. This is contrasted with a more basic understanding of the content of the learning topic, for example comprehension of textbook material. Deep Processing captures the students' desire to learn and their motivation and their willingness to put in time and effort into the learning process. In agreement with Leung and Kember (2003), we suggest that this may be an important prerequisite 
to reflection and intensive reflection. Because other factors found in this analysis were similar to those found in the first study, we feel that these two new factors were the result of the additional items to the survey instrument rather than an indication of a change in the continuum due to different samples in terms of graduating seniors versus MBA alumni and U.S. versus UK students.

\section{Further Validation and Reliability}

This study also sought to provide validation for using the Reflection Hierarchy as a measure of learning for undergraduate programs as well as graduate programs. While this study did add two new dimensions to our previous continuum, we feel that we have improved our model as a measuring tool for both types of programs rather than indicating the need to change models depending on which level of program is being analyzed. The two added dimensions, Deep Processing and Deep Understanding, further delineate levels on the continuum removing some of the grey areas that previously existed. Seven of the eight factors found in this study were highly reliable based on their coefficient alphas, while the eighth, Basic Understanding, was at an acceptable level. In addition, all eight were significant and in the hypothesized direction in predicting overall program evaluation. By including students from two institutions, one from the U.S. and one from the U.K. we have also created a more global instrument for measuring levels of learning across the Reflective Learning Continuum.

\section{Comparing the Programs}

Combined, the U.S. and U.K. student populations surveyed in this study help to validate the six reflective learning dimensions and two conditions for reflection. Although our crosscultural hypotheses were exploratory in nature, there was general support for the notion that U.S. students were more motivated to engage in deep processing, with the result being greater 
reflection and intensive reflection. In many ways, the comparison findings help explain how and why reflective learning takes place. Although untested, it seems plausible that U.S. instructors create a more nurturing environment for deep processing, reflection, and intensive reflection to take place. In contrast, the teaching styles and learning environment associated with the U.K. institution, most notably the large instruction setting, less application of learned materials, and greater reliance on assessment evaluating lecture and book based knowledge, seem to result in a greater focus on basic knowledge and less of a desire for deep processing, reflection, and intensive reflection. The fact that U.S. students rated their educational experience much higher than U.K. students is likely due in part to the deeper learning and personal transformation that they associated with their program.

\section{LIMITATIONS AND FUTURE RESEARCH}

This study attempted to overcome some of the limitations noted with Peltier, Hay and Drago (2005), particularly with regard to graduate students and a single U.S. institution. We also attempted to expand the reflective learning continuum to account for greater scale delineation. In addition to the general limitations associated with the use of student surveys that were noted in our previous study, a remaining limitation is the lower than desired alpha coefficient for the Basic Understanding dimension and the fact that Deep Processing and Habitual Action, though reliable, had only three statements each. We would thus strongly encourage additional research that attempts to further define and delineate our reflective learning continuum, particularly these three aforementioned dimensions.

The comparison findings spark a number of avenues for future research. Although we posited that the greater emphasis on strategic issues and applied focus by instructors contributed to deeper processing, reflection, and intensive reflection in the U.S. institution, we did not 
investigate how different types of learning and evaluation tools impacted any of the learning dimensions. Future research that more closely investigates how the classroom environment and learning tools impact the reflective learning continuum is a promising area of inquiry. Especially promising is research that explores the interactive and sequential nature of the learning continuum. Specifically, our reflective learning continuum was derived in most part from a review of the reflection literature. Although it is logical to assume that habitual action leads to less processing of materials, that instructors motivate reflection, that deep processing leads to deep understanding, and related conceptual arguments, research is clearly needed that examines direct and indirect paths to program evaluation and the interrelationship between individual reflection dimensions and conditions for reflection.

There is also a need to hunt for additional factors likely to foster reflection and intensive reflection. To what extent are variables such as class size, student choice and flexibility, course structure and even course delivery impacting a student's ability to reach higher levels of learning? The impact of different majors within business may also be pertinent. Do accounting majors achieve levels of reflection similarly to marketing and management majors? Demographic characteristics of the learner such as sex, age and educational background may also be found to impact levels of learning along the continuum. Expanding the investigation to additional countries is also warranted. While the existing study begins to provide a global measurement tool for reflective learning, it is noted that the U.S. and U.K. have many similarities and a close historical relationship. Broadening the investigation to other countries would be informative, particularly non Western countries. Finally, as suggested in our first study, making the unit of analysis a course rather than a program offers the potential to measure the degree to 
which particular courses have helped students reach higher levels of reflection. This may also be a way of determining the value of internships.

\section{CONCLUSION}

Recent budget cuts in higher education throughout the U.S. and the U.K. and increased competition due to online delivery and a more mobile world population are pushing universities to find ways to offer efficient yet effective education to a more divergent population. This study has presented a global model of reflective learning that can be used to determine the effectiveness of a program in its ability to encourage students to engage in higher levels of learning including reflection and intensive reflection. We have introduced a new model of the Reflection Learning Continuum that includes two new levels of learning; Deep Processing and Deep Understanding. Deep processing is seen as a measure of learner motivation that may be a necessary step in the learning process to reach higher levels of learning such as reflection and intensive reflection. Deep understanding separates 'understanding' into to dimensions; 'understanding which takes a learner to comprehension but without application and 'deep understanding' which takes a learner to the ability to apply new knowledge to various situations.

The model introduced was based on students' perceptions of two undergraduate business programs, one located in the U.S. and one located in the U.K. As such, it is viewed as being more global in its application and more versatile (as the original model was developed from response by alumni of one university's MBA program). A comparison of mean responses suggested that both programs scored high in terms of reflection and deep learning and both programs did not lead students to indicate habitual action was a common outcome in the learning process. In terms of the higher order learning dimensions the U.S. program tended to reach higher levels than the U.K. program due, in part, to apparent higher levels of instructor/student 
interactions. It is hoped that this study together with our previous one may spur others to

investigate further the Reflective Learning Continuum and those factors which foster higher

levels of learning.

\section{References}

Atkins, S., \& Murphy, K. 1993. Reflection: A review of the literature. Journal of Advanced Nursing, 18: 1188-1192.

Biggs, J., Kember, D., \& Leung, D.Y.P. 2001. The revised two-factor study process questionnaire: RSPQ-2F. British Journal of Educational Psychology, 71: 1333-1349.

Biggs, J. 1987. Student approaches to learning and studying. Melbourne: Australian Council for Educational Research.

Billing, D. 2003. Generic cognitive abilities in higher education: An international analysis of skills sought by stakeholders. Compare, 33 (3): 336-350.

Boyd, E.M., \& Fales, A.W. 1983. Reflective learning: Key to learning from experience. Journal of Humanistic Psychology, 23 (2): 99-117.

Boud, D., Keogh, R., \& Walker, D. 1985. Reflection: turning experience into learning. London: Kegan Page.

Catterall, M., Maclaran, P., and Stevens, L. 2002. Critical reflection in the marketing curriculum. Journal of Marketing Education, 24 (December): 184-192.

Clarke, I., III and Flaherty, T.B. (2003). Challenges and solutions for marketing educators teaching in newly emerging markets, Journal of Marketing Education, 25 (2), 118-129.

Cope, J. 2003. Entrepreneurial learning and critical reflection. Management Learning, 34 (4): 429-450.

Dearing, R. (1997). Higher Education in the Learning Society: report of the national committee of inquiry into higher education. London: HMSO.

Duff, A. (2001). A note on the psychometric properties of the learning styles questionnaire (LSQ). Accounting Education, 10 (2): 185-197.

Eriksen, S.D. (1995). TQM and the transformation from an elite to a mass system of higher education in the UK. Quality Assurance in Higher Education, 3 (1): 14-29.

Government White Paper (2003) The Future of Higher Education, January.

Guardian, (2004). University Guide. (http://education.guardian.co.uk/universityguide2004).

Harrison, M., Short, C., \& Roberts, C. 2003. Reflecting on reflective learning: The case of geography, earth and environmental sciences. Journal of Geography in Higher Education, 27 (2): 133-152.

Hay, A., Peltier, J.W., \& Drago, W.A. 2004. Reflective learning and on-line management education: A comparison of traditional and on-line MBA students. Strategic Change, 13 (4): 169-182

Jones, W. H. 2003. Over the wall: Experiences with multicultural literacy. Journal of Marketing Education, 25 (3): 231-240.

Kember, D., Biggs, J., Leung, D. 2004. Examining the multidimensionality of approaches to learning through the development of a revised version of the learning process questionnaire. British Journal of Educational Psychology, 74 (2): 261-278.

Kember, D. and Leung D.Y.P. 2005. The influence of active learning experiences on the development of graduate capabilities. Studies in Higher Education, 30 (2): 155-160.

Kember, D., Leung D.Y.P., Jones, A., Loke, A.Y., Mckay, J., Sinclair, K., Tse, H., Webb, C., Wong, F.K.Y., Wong, M., \& Yeung, E. 2000. Development of a questionnaire to measure the level of reflective thinking. Assessment and Evaluation in Higher Education, 25 (4): 382-395.

Ledwith, S. and Seymour, D. 2001. Home and away: Preparing students for multicultural management. Journal of Human Resource Management, 12 (8): 1292-1312. 
Leung, D.Y.P., and Kember, D. 2003. The relationship between approaches to learning and reflection upon practice. Educational Psychology, 23 (1): 61- 71.

Liimatainen, L., Poskiparta, M., Karhila, P., \& Sjogren, A. 2001. The development of reflective learning in the contest of health counselling and health promotion during nurse education. Journal of Advanced Nursing, 34 (5): 648-658.

Loo, R. 2002. Journaling: A learning tool for project management training and team-building. Project Management Journal, 33 (4): 61-66.

Maclellan, E. 2004. How effective is the academic essay?.Studies in Higher Education, 29 (1): 75-89.

Marriot, P. 2002. A longitudinal study of undergraduate accounting students' learning style preferences at two UK schools. Accounting Education, 11 (1): 43-62.

Mellahi, K. 2000. The teaching of leadership on UK MBA programmes: A critical analysis from an international perspective. Journal of Management Development, 19 (4): 297-308.

Mezirow J. 1991. Transformative dimensions of adult learning. San Francisco, CA: Jossey Bass

Mullins, L. and Roberts, M. (1996). Assessment strategies: some comparisons between the UK and the US systems of higher education. International Journal of Educational Management, 10 (4): 11-15.

Pee B., Woodman T., Fry H., \& Davenport, E.S. 2000. Practice-based learning: Views in the development of a reflective learning tool. Medical Education, 34: 754-761.

Peltier, J., Hay, A., and Drago, W. 2005. The Reflective Learning Continuum: Reflecting on Reflection, Journal of Marketing Education, WILL NEED TO BE UPDATED

Peltier, J., Drago, W., \& Schibrowsky, J. 2003. Virtual communities and the assessment of online marketing education. Journal of Marketing Education, 25 (3): 260-276.

Slaughter, S. and Leslie, L.L. 1997. Academic capitalism: Politics, policies and the eEntrepreneurial university. London: John Hopkins University Press.

Van Woerkom, M. 2004. The concept of critical reflection and its implications for human resource development. Advances in Developing Human Resources, 6 (2): 178-192.

Van Woerkom, M., Nijhof, W.J., \& Nieuwenhuis, L.F.M. 2002. Critical reflective working behavior: A Survey. Journal of European Industrial Training, 28 (8): 375-383. 


\section{Table 1}

\section{A Comparison of Undergraduate Business Programs}

\begin{tabular}{|c|c|c|}
\hline & U.S. & U.K. \\
\hline Enrollment & 3,200 students & 5,000 students \\
\hline Accreditation & AACSB & None \\
\hline Market & Regional & National \\
\hline $\begin{array}{l}\text { Required } \\
\text { Courses }\end{array}$ & $\begin{array}{l}\text { Business Communications, Business and } \\
\text { Commercial Law, Business Finance, Organization } \\
\text { Behavior, Operations Management, Marketing } \\
\text { Principles, Career Information, Administrative } \\
\text { Policy }\end{array}$ & $\begin{array}{l}\text { Students are required to take a number of 'core' } \\
\text { courses, these include: Work and Organizations, } \\
\text { Markets and Customers, Quantitative Methods for } \\
\text { Business, Corporate Environment, Accounting and } \\
\text { Finances, Business Law, Human Resources, } \\
\text { European Business Environment, Dissertation, } \\
\text { Business Ethics, Strategic Management. }\end{array}$ \\
\hline $\begin{array}{l}\text { Majors } \\
\text { Available }\end{array}$ & $\begin{array}{l}\text { General Business, Accounting, Computer End-User } \\
\text { Technologies, Marketing, General Management, } \\
\text { Finance, Human Resources, Operations, Economics, } \\
\text { Management of Computer Systems (all majors are } 24 \\
\text { credits) }\end{array}$ & $\begin{array}{l}\text { Majors N/A } \\
\text { Students are able to select a number of 'optional' } \\
\text { courses. Illustrative examples include Foreign } \\
\text { Languages, Employment Relations, Corporate } \\
\text { Governance, Employment Law, Game Theory for } \\
\text { Business Strategy and Competitive Marketing } \\
\text { Management. }\end{array}$ \\
\hline $\begin{array}{l}\text { Length of } \\
\text { Program }\end{array}$ & Four years, two years in business programs & Three years full time, four years with placement \\
\hline Class size & $\begin{array}{l}40-50 \text { for core COBE courses, } 30-40 \text { for courses in } \\
\text { the major }\end{array}$ & $\begin{array}{l}\text { Lectures } 250 \text { students (depending on core or optional } \\
\text { choice) Seminar Groups: } 15\end{array}$ \\
\hline $\begin{array}{l}\text { Teaching } \\
\text { Style and } \\
\text { Assessment }\end{array}$ & $\begin{array}{l}\text { Varies across courses and majors, case method of } \\
\text { instruction and team assignments are common. } \\
\text { Considerable contact with instructor and in class } \\
\text { interaction is encouraged. }\end{array}$ & $\begin{array}{l}\text { Varies across courses, integrated lecture and seminar } \\
\text { program is common. Less contact with professor, } \\
\text { large sections are more lecture-based. }\end{array}$ \\
\hline Internships & $\begin{array}{l}3 \text { credit internship is required in } 4 \text { majors, optional } \\
\text { for other majors }\end{array}$ & One year spent at placement organisation \\
\hline $\begin{array}{l}\text { Age of } \\
\text { students }\end{array}$ & Typically $18-22,20-22$ while in program & Typically $18-22$ \\
\hline $\begin{array}{l}\text { Program } \\
\text { Structure }\end{array}$ & $\begin{array}{l}\text { Flexible, students are provided a guideline for } \\
\text { courses to take each semester when they enter the } \\
\text { COBE and select a major, however it is generally up } \\
\text { to the student to select what courses they will take } \\
\text { each semester. Core COBE courses are generally } \\
\text { available each semester and during the summer, } \\
\text { courses in the major may be offered each semester or } \\
\text { every other semester depending on enrollment needs. }\end{array}$ & $\begin{array}{l}\text { The program is subdivided into courses, each } \\
\text { normally worth } 10 \text { or } 20 \text { credit points. Courses are } \\
\text { taken over either a half year ( } 15 \text { weeks) or a whole } \\
\text { year ( } 30 \text { weeks). The program incorporates three } \\
\text { levels of study, each comprising up to } 120 \text { credit } \\
\text { points worth of courses. The program requires } \\
\text { students to take a number of core courses and also } \\
\text { offers students a choice of optional courses. Optional } \\
\text { courses make up } 20 \text { credit points at Level } 2 \text { and } 40 \\
\text { credit points at Level } 3 \text {. }\end{array}$ \\
\hline
\end{tabular}


Table 2

Factor Analysis Results

\begin{tabular}{|c|c|c|c|c|c|c|c|c|}
\hline & Instructor & $\begin{array}{c}\text { Intensive } \\
\text { Reflect } \\
\end{array}$ & Student & Reflect & $\begin{array}{c}\text { Deep } \\
\text { Process } \\
\end{array}$ & $\begin{array}{c}\text { Habitual } \\
\text { Action }\end{array}$ & $\begin{array}{l}\text { Deep } \\
\text { Under } \\
\end{array}$ & $\begin{array}{l}\text { Basic } \\
\text { Under } \\
\end{array}$ \\
\hline Were willing to talk about things that I disagreed with & .68 & & & & & & & \\
\hline Valued my opinions & .65 & & & & & & & \\
\hline Created an atmosphere that allowed me to be open about my views & .65 & & & & & & & \\
\hline Encouraged student questions and comments & .63 & & & & & & & \\
\hline Allowed me to express doubt in what I was learning & .61 & & & & & & & \\
\hline Often asked questions to help me think more deeply & .60 & & & & & & & \\
\hline Encouraged me to think about the implications of what I learned & .55 & & & & & & & \\
\hline Challenged me to think & .45 & & & & & & & \\
\hline As a result of this program I have changed the way I look at myself & & .72 & & & & & & \\
\hline As a result of this program I have changed the way I normally do things & & .71 & & & & & & \\
\hline What I learned forced me to rethink how I view the world & & .64 & & & & & & \\
\hline Course content changed many of my firmly held ideas & & .61 & & & & & & \\
\hline What I learned made me rethink my assumptions about business & & .59 & & & & & & \\
\hline I learned many new things about myself & & .58 & & & & & & \\
\hline What I learned changed how I will do things in the future & & .55 & & & & & & \\
\hline Other students helped me learn about solving real world problems & & & .68 & & & & & \\
\hline There was an open exchange of new ideas between students & & & .66 & & & & & \\
\hline My fellow students valued my opinions & & & .63 & & & & & \\
\hline My fellow students challenged me to think & & & .61 & & & & & \\
\hline I enjoyed learning new ways of thinking from other students & & & .59 & & & & & \\
\hline I sought feedback from others about the decisions that I made & & & .53 & & & & & \\
\hline I thought about what other students did and tried to think of better ways & & & .50 & & & & & \\
\hline I was able to voice my opinion without fear of ridicule by students & & & .44 & & & & & \\
\hline I often re-appraised my experiences so I could learn from them & & & & .72 & & & & \\
\hline I often reflected on my actions to see whether I could improve them & & & & .72 & & & & \\
\hline I often tried to think about how I could do something better next time & & & & .66 & & & & \\
\hline I tried to think about my strengths and weaknesses & & & & .56 & & & & \\
\hline I explored my past experiences as a way of understanding new ideas & & & & .54 & & & & \\
\hline I read it even if it wasn't required & & & & & .71 & & & \\
\hline I made a point of looking at most of the suggested readings & & & & & .65 & & & \\
\hline My goal was to get a good grade regardless of how hard I had to work & & & & & .62 & & & \\
\hline I worked hard at my studies because I found the program interesting & & & & & .53 & & & \\
\hline I found topics interesting and spent extra time seeking more info & & & & & .52 & & & \\
\hline It was important to me that I understood topics completely & & & & & .50 & & & \\
\hline Much of what I learned required little or no thinking & & & & & & -.81 & & \\
\hline Much of what I learned I already knew & & & & & & -.77 & & \\
\hline Course content was repetitious so I often did not need to think & & & & & & -.71 & & \\
\hline Many assignments and tests focused on assessing concepts and theories & & & & & & & .78 & \\
\hline Many assignments and tests focused on strategic/applied issues & & & & & & & .74 & \\
\hline Understanding theory/concepts was important to do well in the program & & & & & & & .72 & \\
\hline $\begin{array}{l}\text { Understanding what was in the assigned text was more important than } \\
\text { understanding how it applied to the current business world }\end{array}$ & & & & & & & & .67 \\
\hline If it was not going to be evaluated, we should not have had to study it & & & & & & & & .64 \\
\hline Memorizing things was often more important than understanding them & & & & & & & & .60 \\
\hline $\begin{array}{l}\text { Content of most courses was interesting but not relevant to the real } \\
\text { world }\end{array}$ & & & & & & & & .57 \\
\hline Coefficient Alphas & .84 & .81 & .79 & .72 & .72 & .71 & .70 & .55 \\
\hline
\end{tabular}


Table 3

Regression Model for Non-Reflection $\leftrightarrow$ Reflection Dimensions

\begin{tabular}{|l|c|l|c|}
\hline $\begin{array}{l}\text { Non-Reflection } \leftrightarrow \text { Reflection } \\
\text { Dimensions }\end{array}$ & $\begin{array}{l}\text { Standardized } \\
\text { Beta Coefficient }\end{array}$ & t-Value & Significance \\
\hline Intensive Reflection & .344 & 9.758 & .001 \\
\hline Deep Understanding & .251 & 7.116 & .001 \\
\hline Reflection & .241 & 6.836 & .001 \\
\hline Habitual Action & -.183 & -5.184 & .001 \\
\hline Deep Processing & .164 & 4.658 & .001 \\
\hline Basic Understanding & -.157 & -4.460 & .001 \\
\hline R-Square $=.33, \mathrm{~F}=39.44$, Model Significant at $\mathrm{p}<.001$ & \\
\hline
\end{tabular}


Table 4

Full Reflection Model

\begin{tabular}{|l|c|c|c|}
\hline $\begin{array}{l}\text { Reflection } \\
\text { Dimension }\end{array}$ & $\begin{array}{l}\text { Standardized } \\
\text { Beta Coefficient }\end{array}$ & t-Value & Significance \\
\hline Intensive Reflection & .344 & 10.958 & .001 \\
\hline Instructor-Student & .331 & 10.537 & .001 \\
\hline Deep Understanding & .251 & 7.991 & .001 \\
\hline Reflection & .241 & 7.676 & .001 \\
\hline Habitual Action & .183 & 5.821 & .001 \\
\hline Student-Student & .180 & 5.747 & .001 \\
\hline Deep Processing & .164 & 5.231 & .001 \\
\hline Basic Understanding & -.157 & -5.008 & .001 \\
\hline R-Square $=.47, \mathrm{~F}=59$, Model Significant at $\mathrm{p}<.001$ \\
\hline
\end{tabular}


Table 5

U.S. vs. U.K Students: Dimension Means

\begin{tabular}{|c|c|c|c|}
\hline $\begin{array}{l}\text { Reflection } \\
\text { Dimension }\end{array}$ & $\begin{array}{c}\text { U.S } \\
\text { Students }\end{array}$ & $\begin{array}{r}\text { U.K. } \\
\text { Students }\end{array}$ & Significance \\
\hline Intensive Reflection & 2.46 & 2.54 & n.s. \\
\hline Reflection & 2.0 & 2.18 & .001 \\
\hline Deep Understanding & 2.14 & 2.06 & n.s. \\
\hline Deep Processing & 2.91 & 3.05 & .05 \\
\hline Basic Understanding & 3.13 & 2.78 & .001 \\
\hline Habitual Action & 3.5 & 3.62 & n.s. \\
\hline Instructor-Student & 2.18 & 2.48 & .001 \\
\hline Student-Student & 2.39 & 2.46 & n.s. \\
\hline Overall Program Evaluation & 1.93 & 2.30 & .001 \\
\hline
\end{tabular}


Table 6

Comparison of U.S. and U.K. Students on Individual Questions

\begin{tabular}{|c|c|c|c|}
\hline \multirow[b]{2}{*}{ REFLECTION DIMENSION } & \multicolumn{2}{|c|}{ Students } & \multirow{2}{*}{$\begin{array}{l}\text { Mean } \\
\text { Diff }\end{array}$} \\
\hline & U.S & U.K. & \\
\hline \multicolumn{4}{|l|}{ Intensive Reflection } \\
\hline What I learned changed how I will do things in the future & 2.14 & 2.47 & -.3 \\
\hline I learned many new things about myself & 2.08 & 2.28 & $-.2 *$ \\
\hline \multicolumn{4}{|l|}{ Reflection } \\
\hline I often tried to think about how I could do something better next time & 1.65 & 1.99 & -0.34 \\
\hline I often re-appraised my experiences so I could learn from them & 2.16 & 2.45 & -0.29 \\
\hline I tried to think about my strengths and weaknesses & 2 & 2.28 & -0.28 \\
\hline I often reflected on my actions to see whether I could improve them & 2.09 & 2.29 & -0.2 \\
\hline I explored my past experiences as a way of understanding new ideas & 1.94 & 2.12 & $-0.18^{*}$ \\
\hline I often questioned whether I was doing things right & 2.15 & 1.94 & $0.21 *$ \\
\hline \multicolumn{4}{|l|}{ Deep Processing } \\
\hline I worked hard at my studies because I found the program interesting & 2.42 & 2.78 & -.36 \\
\hline I found topics interesting and spent extra time seeking more information & 2.96 & 3.24 & -.28 \\
\hline I read it even if it wasn't required & 3.73 & 3.92 & $-.19 *$ \\
\hline \multicolumn{4}{|l|}{ Deep Understanding } \\
\hline Many assignments and tests focused on assessing concepts and theories & 2.27 & 2.05 & .22 \\
\hline \multicolumn{4}{|l|}{ Basic Understanding } \\
\hline $\begin{array}{l}\text { Understanding what was in the assigned text was more important than understanding } \\
\text { how it applied to the current business world }\end{array}$ & 3.28 & 2.81 & 0.47 \\
\hline If it was not going to be evaluated, we should not have had to study it & 3.04 & 2.62 & 0.42 \\
\hline Content of most courses was interesting but not very relevant to the real world & 3.32 & 3.02 & 0.30 \\
\hline \multicolumn{4}{|l|}{ Instructor-to-Student Interaction } \\
\hline Valued my opinions & 2.3 & 2.8 & -0.5 \\
\hline Created an atmosphere that allowed me to be open about my views & 2.12 & 2.51 & -0.39 \\
\hline Challenged me to think & 1.85 & 2.19 & -0.34 \\
\hline Encouraged me to think about the implications of what I learned & 2.09 & 2.4 & -0.31 \\
\hline Encouraged student questions and comments & 1.91 & 2.19 & -0.28 \\
\hline Were willing to talk about things that I disagreed with & 2.4 & 2.63 & -0.23 \\
\hline Often asked questions to help me think more deeply & 2.16 & 2.38 & -0.22 \\
\hline \multicolumn{4}{|l|}{ Student-to-Student Interaction } \\
\hline I was able to voice my opinion without fear of ridicule by other students & 2.16 & 2.42 & -.26 \\
\hline I thought about what other students did and tried to think of better ways & 2.29 & 2.49 & $-.20 *$ \\
\hline
\end{tabular}




\section{Figure 1 \\ Model of Reflective Learning}

\section{Learning Conditions}

\begin{tabular}{|l|}
\hline $\mathbf{R}$ \\
$\mathbf{E}$ \\
$\mathbf{F}$ \\
$\mathbf{L}$ \\
$\mathbf{E}$ \\
$\mathbf{C}$ \\
$\mathbf{T}$ \\
$\mathbf{I}$ \\
$\mathbf{O}$ \\
$\mathbf{N}$ \\
\\
$\mathbf{H}$ \\
$\mathbf{I}$ \\
$\mathbf{E}$ \\
$\mathbf{R}$ \\
$\mathbf{A}$ \\
$\mathbf{R}$ \\
$\mathbf{C}$ \\
$\mathbf{H}$ \\
$\mathbf{Y}$ \\
\hline
\end{tabular}

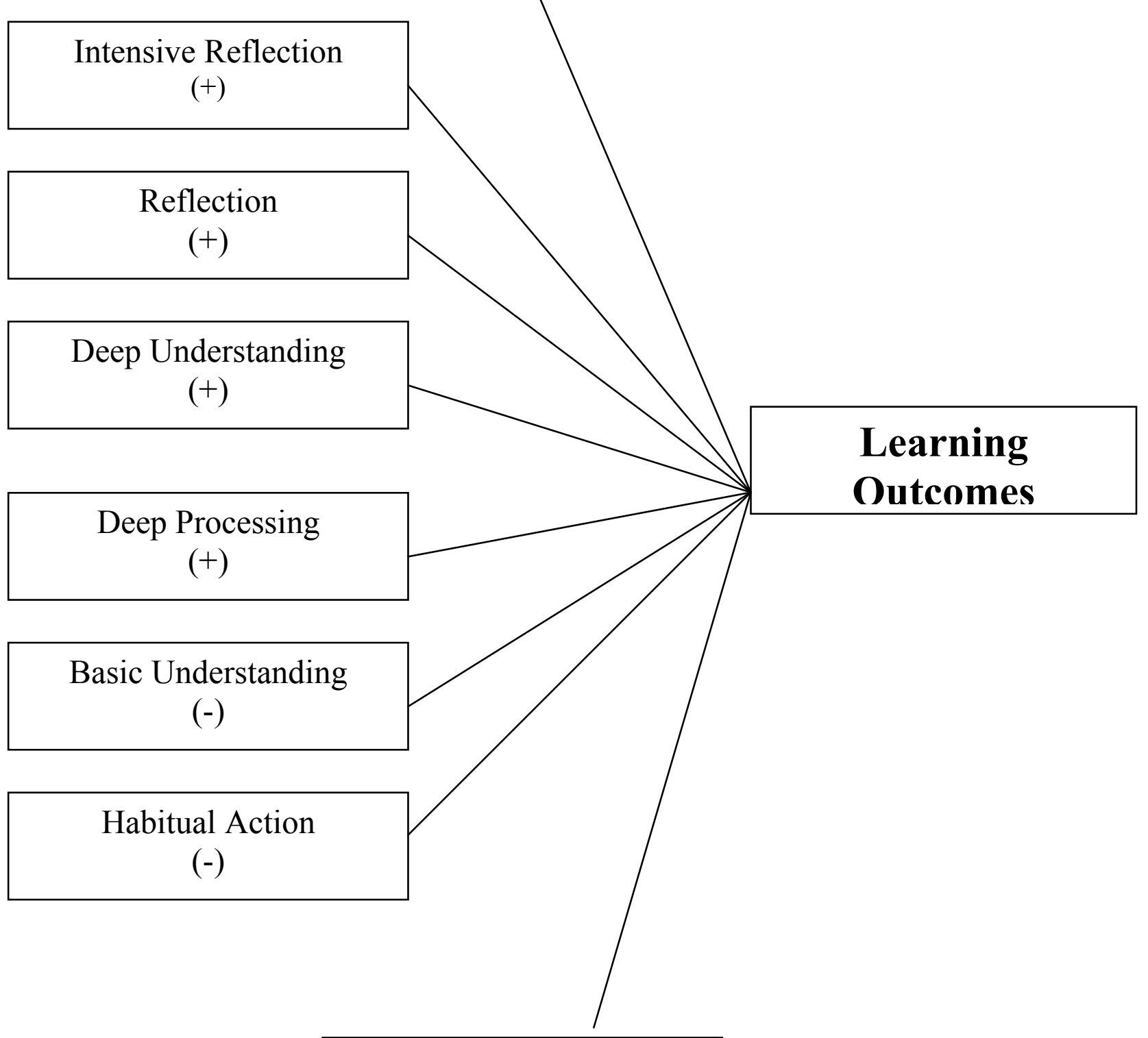

\section{Student-to-Student Interactions $(+)$}

